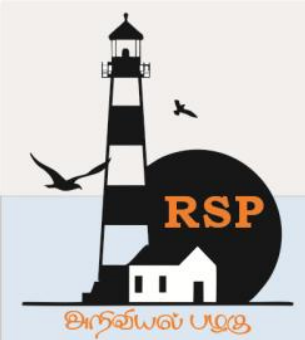

INTERNATIONAL RESEARCH JOURNAL ON ADVANCED SCIENCE HUB

Open Access
Open

RSP SCIENCE HUB

(The Hub of Research Ideas)

Available online at www.rspsciencehub.com

\title{
Need of Energy Audit in Everyday Life
}

Muniyandy Elangovan ${ }^{1}$, A T Ravichandran ${ }^{2}$, Prabhukumar Chellamuthu ${ }^{3}$

${ }^{1}$ Professor, Mechanical Department, Vel Tech Rangarajan Dr. Sagunthala R\&D Institute of Science and Technology, Chennai, Tamilnadu, India

${ }^{2}$ Dean of SOMC, Mechanical Department, Vel Tech Rangarajan Dr. Sagunthala R\&D Institute of Science and Technology, Chennai, Tamilnadu, India

${ }^{3}$ Assitant Professor, Mechanical Department, Vel Tech Rangarajan Dr. Sagunthala R\&D Institute of Science and Technology, Chennai, Tamilnadu, India

muniyandy.e@gmail.com ${ }^{1}$

\begin{abstract}
Life is unimaginable without energy because we depend on different forms of energy in our day to day activities. Authors have discussed the importance of energy in human life and how it can be optimized to reduce the consumption by following certain procedures at different working places. Audit types and carrying out approaches are discussed with a methodology to execute the conservation of energy in daily life. Value of energy is discussed as a citizen point of view from different users like Students, Teachers, Family members, officers and employees. The need and importance of energy conservation and audit are discussed for today's technological world
\end{abstract}

Keywords: Energy audit, Energy conservation, Energy analysis, Power Consumption.

\section{Introduction}

Availability of Conventional energy source is predicted for a maximum period of hundred years. Research on alternate energy and fuels other than coal has been started around the world [1,2]. Renewable-energy sources are being used for commercial purpose, and it is inevitable in the future. Only drawback of renewable energy is, it is impossible to get for the entire year because of the climate change (seasons) in a year. Generating energy is not the responsibility of one individual human, whereas the consumption of energy can be controlled or can be used effectively by an individual person.

Though many forms of energy are used by human, but the scope is limited to electrical energy, thermal energy, and mechanical energy in this paper. Today's technological world, human life moves with electrical energy because of the development in every industry. Day starts with alarm to get up in the morning by battery-operated clock or mobile. Satellite technology brought the world communication very simple and much cheaper when compared to ten years ago. This communication is helping to do business internationally and bring good coordination to deliver a service without any delay and independent of user stationed place. Before the invention of electricity, human life moves around the SUN and there was no work after sunset. Nowadays, electricity is available for $24 \mathrm{hrs}$ and people started working without any break in customer services because of the development in telecommunication, which depends on electricity (electrical energy).

Users are not expected to know the source or availability. In fact, many products are produced from crude oil but people are not aware. Similarly, electricity generation resource (Hydel \& Thermal) is less in India and therefore, nuclear energy-based electricity is being operated because of increasing electricity demands and at the same time, safety must be taken care. The need of electricity is 


\section{www.rspsciencehub.com}

increasing whereas the natural recourse are getting reduced to produce energy. Of course, the Government needs to do research for alternative energy generation and at the same time; it must be brought to the user about the importance of electrical energy to use with clear knowledge. Authors' intention is to adopt energy conservation and audit (ENCONDIT) in every one's mind, which can support the entire society, industry, and nation [3-8].

An energy audit is a mechanism to evaluate the usage of energy for the defined work/job/product/service, waste of energy, and optimum use of energy and to give suggestions or solutions to improve the energy usage by adopting changes in the system or adding new technology to reduce energy consumption. These are to be brought into everyone's mind to care about energy usage, and audits must be done automatically seeing any service and product. These points are to be discussed in detail.

\section{Energy Conservation}

Energy conservation is the reduction of energy consumption by an effort, and it can be achieved by the development of the process. In general, energy reduction can be done only with expert knowledge in any particular domain, but in practical; it is not necessary. Understanding the system of any service or product can fetch an idea to reduce energy consumption. People are always motivated/aimed to achieve maximum gain in a short period. It depends on the services, saving small quantities for the long run can bring better saving in energy and reduce the emission level to the environment. It might look like energy conservation similar to energy efficiency. Energy efficiency is for the particular product or service energy consumption is reduced without affecting the quality, defined purpose and expected output. It is understood that efficiency can be achieved by engineering or deep knowledge in a particular function or product whereas, for energy conservation, users can have little motivation towards the value of energy. For the same process or product, there can be multiple ways to reduce the energy consumption, and it can be achieved only when the options are given to the user and the society to contribute toward energy conservation.
Volume 02 Issue 11 November 2020

Energy conservation can benefit every individual, society and nation in different forms and few can be listed as.

i. The first and the most direct benefit is the reduction in electricity bills.

ii. Improving the process in energy reduction can lead to reducing the overall cost of the product or service.

iii. Reducing the energy and improving the process can directly support profit to the company.

iv. Energy reduction shows the performance of the process which intern increases the value in the market as a quality product.

v. Presenting this energy performance as the product or service as labelling, the company brand gets marketed by the customer or user.

vi. Saving the energy directly causes reduction in emission, which supports for a healthy environment.

vii. Reduces the import quantity of fossil-fuel materials for the energy generation.

viii. By reducing the energy, the estimated period of resource availability can be increased.

\section{Energy Audit}

An energy audit can be carried out on any company to estimate the energy consumption with respect to the designed or expected power consumption and to evaluate the overall energy management of energy distribution. It also asses the total energy consumption for the process or product as input and output from the targeted task. Overall, the balancing of energy needs to be evaluated, and possible opportunity needs to be identified to reduce the energy consumptions. In a nutshell, it can be called VMA, which means verifying the data, monitor the energy flow and analyze the complete system from the technical and financial point of view for the recommendation, and action plans to be carried out.

\subsection{Types of Audit}

It depends on the request from the company and the type of industry, audit need to be carried. The audit can be classified into three types, which are shown in figure 1. Let us discuss on each type. 


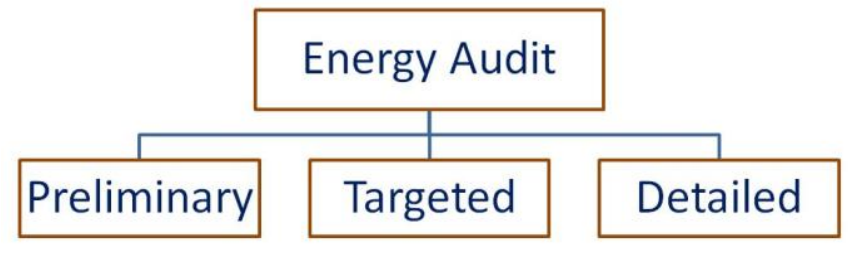

\section{Fig.1. Energy Audit Types 3.2 Preliminary Energy Audit}

This is recommended for the quick reports where energy consumption of the complete company can be analyzed from the given data and to estimate the energy-saving possibilities. Energy consumption is analyzed for the major equipments without going into details. The outcome of this audit can recommend for a detail audit with clear evidence and easily implementable suggestions/solutions can be given to reduce energy consumption.

\subsection{Targeted Energy Audit}

This audit is an outcome of the preliminary audit, because during the initial audit, based on the observation or shared data, auditors can ask for a detailed audit to improve the targeted process or system. A targeted audit can be for the piping system alone, lighting system, thermal insulation or any other single task. In this study, detailed data collection, measurement, energy balancing, thermal analyses are carried out and the cost analysis to implement any action/recommendation to reduce the energy consumption is required.

\subsection{Detailed Energy Audit}

This is the most preferred audit because it can include a detailed evaluation of energy consumed and wasted from the balancing of an energy system. This audit is done for the entire unit and detailed connection between different projects. It brings out the detailed cost analysis for the current energy flow and suggests various options to reduce the energy savings' implementation under three categories as shown in figure 2.

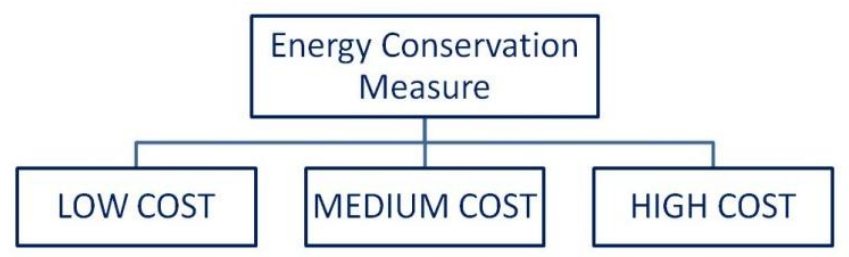

Fig.2. ENCON Measure

\section{Methodology to conduct the Energy Audit}

To carry out an audit, there is a systematic approach which is defined in ISO14001 and Bureau of Energy-Efficiency guidelines. The complete audits can be grouped into three-level or phases as (i) Pre-Audit, (ii) Audit and (iii) PostAudit [1]. All the activity which includes planning, initial visit, data collection, meeting key members, analysis of the plant, measuring and recording energy flow, cost analysis, reporting, etc. can be covered. Let us explore each phase in detail.

\subsection{Pre Audit}

As soon as an enquiry comes from the company, request for an initial visit to the site as an auditor. Before visiting, try to get plant layout, kind of service or product, and scope of work. Maximum data for earlier history, audit report and implemented action plan and outcomes can be discussed with the energy manager. Meeting top management can give an idea on an expectation from the audit, whether management is willing to go for a lot of investments to improve the energy conservation on updating technologies or processes. During the visit, identify the major equipment and processes in order to bring the required team members and instruments to measure the energy data. Time to explain the need for detailed audit and duration of audit can be planned, which depends on audit level and plant size.

\subsection{Audit}

This is the stage to make a detailed study of the entire company process and equipment during operation or running the plant. Depending upon the operation, timing can be fixed as either day time or night time and the need for running each equipment duration to explore the energy losses. Make sure that the operational capacities of major equipment are to be measured with respect to the designed capacity. Get an idea about the currently implemented techniques or training program, to reduce the energy consumption and interact with concerned supervisor and operator of the equipment. Inlet sources of energy details are to be collected to know the expenses on a tariff which can help to prepare a cost analysis at the end. Energy analysis must have details of the type of energy consumed to be tabulated/balanced by the department, process, major equipment, and product. A similar approach can be used for the 


\section{www.rspsciencehub.com}

raw material quality and quantity used in the plant and if possible flow diagram can be received or need to be prepared for the material \& energy analysis.

Energy Audit Report: This is an output from the audit which needs to be prepared for the client display about the complete energy management in a company from the inlet of energy to the distribution of energy, material, waste in every subset inside the plant. All the observation analysis date must be presented in a systematic with major subheadings to cover all findings. As an example, any report can have minimum heading as an acknowledgement, Team, executive summary, plant layout, and process flow diagram, energy balancing diagram, conservation opportunities, conservation measure, action plan, economic analysis, recommendation and reference to list the shared data.

\subsection{Post Audit}

From the defined action plan, an implementation must be started to monitor the energy as per the schedule and interpret the consequences from the collected data to realize/evaluate it. Based on the report, additional monitoring/meters are to be installed wherever necessary and start the training program to awareness of new implementation and explain the purpose \& effect in energy consumption. At last, do not forget to get the feedback.

\section{Implementation of AUDIT recommendation}

In General, Energy Conservation (ENCON) is analyzed during the audit. In ENCON, energy balancing study and the possible root cause of electrical energy are identified by measuring the power meter, the thermal loss is identified by taking thermal photos; efficiency of the equipment or system is analyzed from the input and output of the system. After the audit, a report is prepared with a recommendation to reduce the energy waste or improve the process of the system by adopting or implementing a few changes or changing some procedures. This recommendation can be simplified under three categories as (i) LOW COST (ii) MEDIUM COST and HIGH COST.
Low-cost solution also called ZERO COST because this kind of suggestion brings out some new procedure or awareness program to an employee which does not cost much. Therefore, it is called as zero cost. In the second suggestion, the investment will be the medium which depends on company investment in the total project, and can be evaluated by auditor calculation on the technical and economic study. This is preferred for the MUST option where these are to be implemented to avoid known losses. Many cases, it can be delayed and cannot be avoided by this implementation. The last option is high-cost solutions, which need huge investment. This decision can be taken by management depending on their willingness to implement based on the recovery period.

\section{ENCON in everyday life}

Conservation of energy in the industry is welldefined and easy to verify. In family life or social life, lots of energy are wasted or consumed without any individual knowledge because of negligence. In-home, energy can be water, electricity, manhour, food, etc. Though many forms of energy are wasted, it is not taken into consideration. Even a small leakage in pipe or valve can lead the loss of 0.5 cubic meter water at one place in a day. Presently, water meters are not connected, and society does not bother about this water wastage. Similarly for the fans which are not switched off, one fan can cause a loss of $15 \mathrm{KWh}$ per month. These facts need to be communicated, and all family members must be aware of the consequence of any careless activity. In some of the houses, during daytime also tube lights, bulbs or other devices are used for lighting purpose even though sufficient sunlight reaching the home. Wasted energies at home are not estimated for the long run about the additional consumption of power and wasting resources. Use of two wheelers or four wheelers is good for long-distance travel but people in society use even for a distance of $50 \mathrm{~m}$ because of habituation. In olden days, foods wastes are used for domestic animals like cows, goat, and dogs. In today's city life, wasted foods are going to garbage. It is understandable that wastages are considered as a money loss. Figure 3 shows few ways of Energy Loss. 
www.rspsciencehub.com

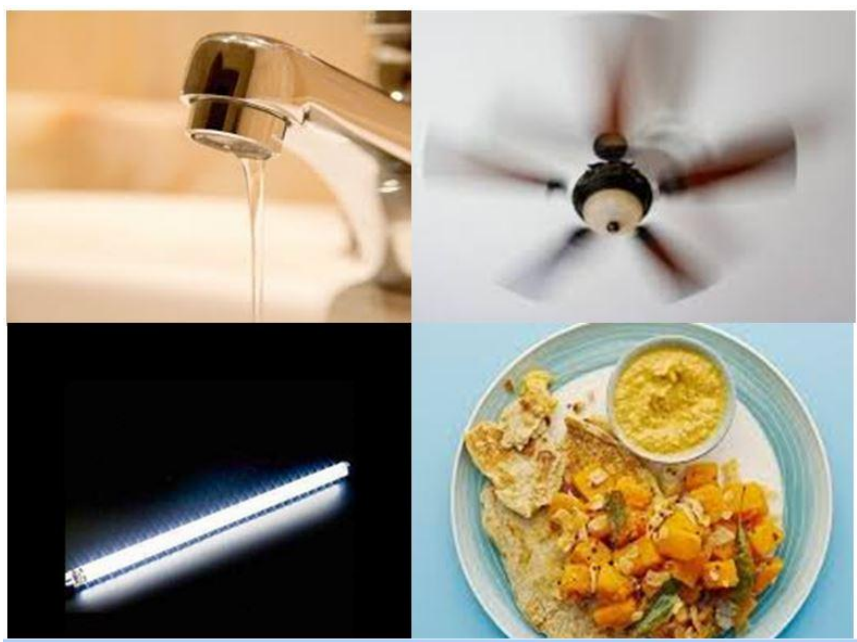

Fig.3. Energy Loss

\section{Energy Conservation and Audit (ENCONDIT) in LIFE}

In industry practice, energy conservation and implementations are happening at two different stages because of the existing hierarchy and infrastructure. In everyday life, these need to happen together. The loss which is happening in the industry can be monitored by the concerned team and proper maintenance is done. As per the standard, all employees are given awareness program and required training to avoid these kinds of losses. Whereas at home, you need to establish awareness and keep feeding information to all members. It is not easy to reach every family and give training to all members by the Government. Authors recommend that schools and colleges are the right place to introduce the importance of energy and effect of energy loss at home, school, colleges, and other places. Students are the right ambassadors to bring energy importance to home. Recently, central government has introduced "CLEAN INDA" from the school and reached the maximum. A similar approach can work but this needs continuous monitoring and implementation. That for college students, this approach can help in multiple ways because of their roles in different places. Boy/Girl is a student at university, son/daughter at home and future employee or entrepreneur in any company and parent in the future. College students can easily bring changes at home towards energy conservation and losses because parents accept suggestions from their son/daughter easily. Students are the right point to educate and start energy conservation.

In previous section, we studied different energy losses at home. These are to be corrected at that moment itself. It cannot be delayed or postponed for next moment because of the continuous loss. In industry, more human resources are there to observe the incident and a lot of possibility that someone can take care of those losses. Whereas at home, only family members are there, and all are in a hurry to leave the home because of everyday routine work. If any family member see water flowing in a water tap, he/she has to close the tap at that time itself, because it is not sure that when other members will go to that place and stop the energy loss. Whatever may be the loss, for any particular incident but the loss is not for the family, and it can affect the society.

By educating a student, lots of electricity loss can be reduced at university. It is observed that in most of the class room's fans and lights are not switched off while leaving the class room, and it is switched off after class hours by the concerned maintenance team. The importance of energy and loss of energy in class room and in home can be explained to a student. Small losses like water leakage, fan and lights are $\mathrm{ON}$ at class room, which is not taken by students because ignorance. Ignorance comes because society failed to educate students. University has the responsibility to educate the students with energy conservation and audit knowledge. By educating and providing awareness programmes, we can bring a lot of saving in terms of electricity and water, which are easily measurable every month.

\section{Conclusions}

The importance of energy conservation in everyday life was discussed, which can help every individual to think about the proper utilization of energy. Presenting from the user's point of view, it is more meaningful to realize the value of energy. Industry audit procedure was discussed considering the domestic applications, and huge energy consumption can be targeted. Present system of implementing conservation procedure and audit methods are to be started from home to industry. This ENCONDIT approach seems to be practically possible by the individual in society. Energy conservation and optimization can lead to a healthy environment by utilizing optimum energy. It is recommended to have non-credit online course with a maximum duration of 15 hours can bring more awareness among young and future engineers who are going to rule the engineering nation. 


\section{References}

[1] Bureau of Energy Efficiency: General Aspects of Energy Management and Energy Audit, New Delhi, 2015

[2] Gopi Srinath and N Uday Kumar: Energy Audit as Tool for Improving System Efficiency in Industrial Sector, Int. Journal of Engineering Research and Applications, Vol 4, Issue 6, June 2014.

[3] Nitin kumar and Jitender Singh: Energy Audit of a College Campus, International Journal of Advances in Engineering \& Scientific Research, Vol.4, Issue 5, JullAug -2017.

[4] Gousia Sultana, Harsha.H.U, “ Electrical Energy Audit a Case Study”, IOSR Journal of Electrical and Electronics Engineering (IOSR-JEEE) e-ISSN: 2278-1676,p-ISSN: 2320-3331, Volume 10, Issue 3 Ver. III (May - Jun. 2015), PP 01-06

[5] Ashok Kumar Pandey, Ravi Prakash," Energy Conservation Opportunities in Pulp \& Paper Industry",, Open Journal of Energy Efficiency, 2018, 7, 89-99 http://www.scirp.org/journal/ojee, ISSN Online: 2169-2645

[6] Ankit Tandon, Jitendra Kasera, Mr.Manish Pokharna," "Energy Audit and Management", International Journal of Latest Technology in Engineering Management \& Applied Science (IJLTEMAS), VOLUME 1, ISSUE 3, JUNE 2012, ISSN 2278 - 2540

[7] M.Bala Raghav, M.Sravya Srijaa, G.Srinivasa Rao, K.Naga Bhavya, Y.Suchitra," ENERGY CONSERVATION AND AUDIT-A CASE STUDY", International Journal of Advanced Research in Electrical, Electronics and Instrumentation Engineering, (An ISO 3297: 2007 Certified Organization) Vol. 2, Issue 10, October 2013

[8] Shradha Chandrakant Deshmukh, Varsha Arjun Patil," Energy Conservation and Audit", International Journal of Scientific and Research Publications, Volume 3, Issue 8, August 2013, 